\title{
Calibration of channel depth and friction parameters in the LISFLOOD-FP hydraulic model using medium- resolution SAR data and identifiability techniques
}

\author{
Melissa Wood ${ }^{1,2}$, Renaud Hostache ${ }^{2}$, Jeffrey Neal ${ }^{1}$, Thorsten Wagener ${ }^{3}$, Laura Giustarini $^{2}$, Marco Chini $^{2}$, \\ Giovani Corato ${ }^{2}$, Patrick Matgen ${ }^{2}$, and Paul Bates ${ }^{1}$ \\ ${ }^{1}$ School of Geographical Sciences, University of Bristol, University Road, Bristol, BS8 1SS, UK \\ ${ }^{2}$ Luxembourg Institute of Science and Technology (LIST), 41 rue du Brill, 4422 Belvaux, Luxembourg \\ ${ }^{3}$ School of Engineering, University of Bristol, Queen's Building, University Walk, Bristol, BS8 1TR, UK
}

Correspondence to: Melissa Wood (m.wood@bristol.ac.uk)

Received: 24 November 2015 - Published in Hydrol. Earth Syst. Sci. Discuss.: 18 January 2016

Revised: 8 November 2016 - Accepted: 15 November 2016 - Published: 19 December 2016

\begin{abstract}
Single satellite synthetic aperture radar (SAR) data are now regularly used to estimate hydraulic model parameters such as channel roughness, depth and water slope. However, despite channel geometry being critical to the application of hydraulic models and poorly known a priori, it is not frequently the object of calibration. This paper presents a unique method to simultaneously calibrate the bankfull channel depth and channel roughness parameters within a 2-D LISFLOOD-FP hydraulic model using an archive of moderate-resolution $(150 \mathrm{~m})$ ENVISAT satellite SAR-derived flood extent maps and a binary performance measure for a $30 \times 50 \mathrm{~km}$ domain covering the confluence of the rivers Severn and Avon in the UK. The unknown channel parameters are located by a novel technique utilising the information content and dynamic identifiability analysis (DYNIA) (Wagener et al., 2003) of single and combinations of SAR flood extent maps to find the optimum satellite images for model calibration. Highest information content is found in those SAR flood maps acquired near the peak of the flood hydrograph, and improves when more images are combined. We found that model sensitivity to variation in channel depth is greater than for channel roughness and a successful calibration for depth could only be obtained when channel roughness values were confined to a plausible range. The calibrated reach-average channel depth was within $0.9 \mathrm{~m}(16 \%$ error) of the equivalent value determined from river cross-
\end{abstract}

section survey data, demonstrating that a series of moderateresolution SAR data can be used to successfully calibrate the depth parameters of a 2-D hydraulic model.

\section{Introduction}

Flooding of over one-third of the world's land area affected more than 2 billion people - $38 \%$ of the world's population - between 1985 and 2003 (Dilley et al., 2005). Climate change forecasts also indicate that in the future there may be an increase in the frequency and pattern of flooding (European Environment Agency, 2012; European Commission, 2014; IPCC, 2014). One response to this global hazard has been an increasing demand for better flood forecasts (Schumann et al., 2009a). Flood inundation models have an important role in flood forecasting and there has been scientific interest in combining direct observations of flooding from remote sources with these inundation models to improve predictions because of the persistent decline in the number of operational gauging stations (Biancamaria et al., 2011a), as well as the reality that many river basins are inaccessible for ground measurement. Synthetic aperture radar (SAR) satellites have particular importance in this respect as they can discriminate between land and smooth open water surfaces over large scales. These microwave (radar) frequency satel- 
lites are capable of all-weather day/night observations and this makes them a particularly attractive option for observing floods. Currently active SAR satellites include RADARSAT2, ALSOS-2/PALSAR-2, TerraSAR-X, TanDEM-X, Sentinel $1 \mathrm{a}$ and $1 \mathrm{~b}$ and the COSMO SkyMed constellation. Historic data are also available from SAR satellites now out of operation such as ENVISAT, ERS1 and 2 and RADARSAT1.

By processing SAR data, it is possible to produce binary maps of flood extent that can then be used either on their own or intersected with a digital elevation model (DEM) to produce shoreline water levels for model calibration and validation. Integration of SAR data with models is an established technique for reducing uncertainty in model predictions, as it updates/calibrates the model states/parameters with observed data (e.g. Andreadis et al., 2007; Biancamaria et al., 2011b; Domeneghetti et al., 2014; Giustarini et al., 2011; Garcia-Pintado et al., 2013, 2015; Hostache et al., 2009; Matgen et al., 2010; Mason et al., 2009, 2012; Montanari et al., 2009; Tarpanelli et al., 2013; Yan et al., 2014), with the aim of improving flood forecasts. Naturally, calibration of these hydraulic models is essential for accurate results, and calibration studies to date have largely focused on roughness. Aronica et al. (2002), Tarpanelli et al. (2013), Hall et al. (2005), Schumann et al. (2007) and Di Baldassarre et al. (2009a, 2010, 2011) have used flood extent maps to successfully find best-fit roughness parameter values. Mason et al. (2003) point to roughness being a dominant factor for shallow reaches in particular and Di Baldassarre et al. (2009b) found that the optimal roughness parameters depend on the timing of the SAR image and the magnitude of the flood event. Given this prior research, historic observations of flooding should have a particular role in model calibration and sensitivity testing.

The provision of good bathymetric data is also critical to the application of hydraulic models (Trigg et al., 2009; Legleiter and Roberts, 2009; Yan et al., 2015). Yet generally there are few ways to obtain bathymetry information for hydraulic models where no ground data measurements exist. River depth may be estimated (e.g. Durand et al., 2010 employed an algorithm based on the Manning equation or Moramarco et al., 2013 who created an entropy depth distribution using surface flow velocity data) or measured with optical satellites using reflectance as done by Legleiter and Roberts (2009) (though the method is best suited for clear and shallow streams). Hostache et al. (2015) also proposed a drifting GPS buoy to assimilate water elevation and slope data into a hydraulic model to define riverbed bathymetry, but overall passive and remote mechanisms are scarce. Spatially distributed river depths are rarely available and there is a strong argument that where channel geometry is a priori unknown it should also be estimated through calibration.

It has commonly been thought that channel geometry and roughness traded off against each other (e.g. as in the wellknown Manning equation) and therefore that they could not be uniquely identified at the same time. However, GarciaPintado et al. (2015) estimated channel friction and spatially variable channel bathymetry together using water levels derived from a sequence of real SAR overpasses $(3 \mathrm{~m}$ resolution data from the COSMO-SkyMed constellation of satellites) and the ensemble transform Kalman filter. Durand et al. (2008) demonstrated that estimates of depth and water (i.e. friction) slope could be derived simultaneously from synthetic observations of water surface elevation integrated with a hydraulic model, though this research related more specifically to depth of flow, rather than depth of channel. Yoon et al. (2012) were also able to derive bed elevations from similar synthetic data. Mersel et al. (2013) progressed this further by proposing a slope-break method to locate optimal locations to measure flow depth, through low to high flows over time, using synthetic data. Durand et al. (2008), Yoon et al. (2012) and Mersel et al. (2013) used synthetic altimetry data which were created within the context of the upcoming Surface Water and Ocean Topography (SWOT) mission that will be able to resolve rivers over $100 \mathrm{~m}$ wide only.

Research to date has therefore demonstrated the feasibility of calibrating hydraulic model parameters governing channel depth and channel roughness simultaneously. This has been achieved using the higher-spectrum-resolution (up to $50 \mathrm{~m}$ ) SAR images of flood extent. But because pixel size is inversely proportional to orbit revisit time, high-resolution data are available only infrequently. There is thus some benefit to also exploring the use of existing moderate-resolution (50 to $300 \mathrm{~m}$ ) SAR data (such as the archive of $150 \mathrm{~m}$ resolution ENVISAT wide swath mode) to understand more about how channel depth and friction can be identified concurrently using coarser-resolution SARs, and whether a single SAR flood map is sufficient to achieve this or if a sequence of flood maps is more beneficial.

Therefore, the aim of this paper is to draw on this prior research for simultaneous channel roughness and depth calibration and extend it to determine whether mediumresolution SAR data can be used to concurrently estimate channel friction and geometry parameters in a hydraulic model. If so, a secondary aim is to determine if a single SARderived flood map is sufficient to do this or if a sequence of flood maps is more useful. For this, the identifiability technique presented by Wagener et al. (2003), namely dynamic identifiability analysis (DYNIA) is utilised. The objective of this paper is therefore to test the utility of the DYNIA identifiability technique in this specific context to find the SAR images with high parameter information and locate the likely optimum parameter values. This methodology particularly uses flood extent with an accuracy-scoring method that disregards the correct detection of "no water" pixels.

In Sect. 2, we describe the methodology with information on the hydraulic model, the data needed to run it and the methods used to select the range of model parameters. There is also an introduction to the procedure used to process the satellite data and create flood extent maps. Section 3 de- 
scribes the study area and data used, whilst Sect. 4 presents and discusses the results (including whether SAR observations at particular times during a flood or particular combinations of images are more successful). Conclusions are presented in Sect. 5.

\section{Method}

\subsection{Hydraulic model}

We use the LISFLOOD-FP hydraulic model with the subgrid formulation of Neal et al. (2012) to simulate flood flows. LISFLOOD-FP (Bates and De Roo, 2000) is a 2-D hydraulic model for subcritical flow that solves the local inertial form of the shallow water equations using a finite difference method on a staggered grid. As input, the model requires ground elevation data describing the floodplain topography, channel bathymetry information (river width, depth and shape), boundary condition data consisting of discharge time series at all inflow points to the domain, water surface elevation time series at all outflow points and friction parameters which typically distinguish different values for the channel and floodplain. Of these data, floodplain topography information is readily available from airborne and satellite digital elevation models, boundary condition data can be taken from ground gauges, hydrologic models or statistical distributions and friction parameters are typically estimated from lookup tables or calibrated. Channel bathymetry can be taken from ground-surveyed cross sections; however, for much of the planet no such measurements exist and are impossible to obtain remotely. In this situation, channel bathymetry is a priori unknown and it is therefore sensible to also treat it as a parameter that must be calibrated along with the friction.

In order to describe bathymetry as a calibrated variable in this experiment, river channel depth was parameterised as a linear scaling of reach-average width. In general, this linear approach will not be appropriate over an entire river network where the reach-averaged width to depth relationship would be expected to change with bankfull discharge. However, the width of the river chosen as a test case for this paper is constant along the simulated reach, while we assume the depth of tributaries has an insignificant impact on the flooding on the main stem. In effect, the optimisation problem therefore simplifies to estimating reach-averaged bankfull depth and Manning's $n_{\mathrm{c}}$ for a channel of reach-average width. In widthvarying river systems, a dual parameterisation approach for depth and width could be adopted but would substantially complicate the parameter estimation problem. The floodplain Manning's roughness coefficient was assumed constant in these experiments as previous tests have shown that the model was less sensitive to floodplain friction than channel friction.

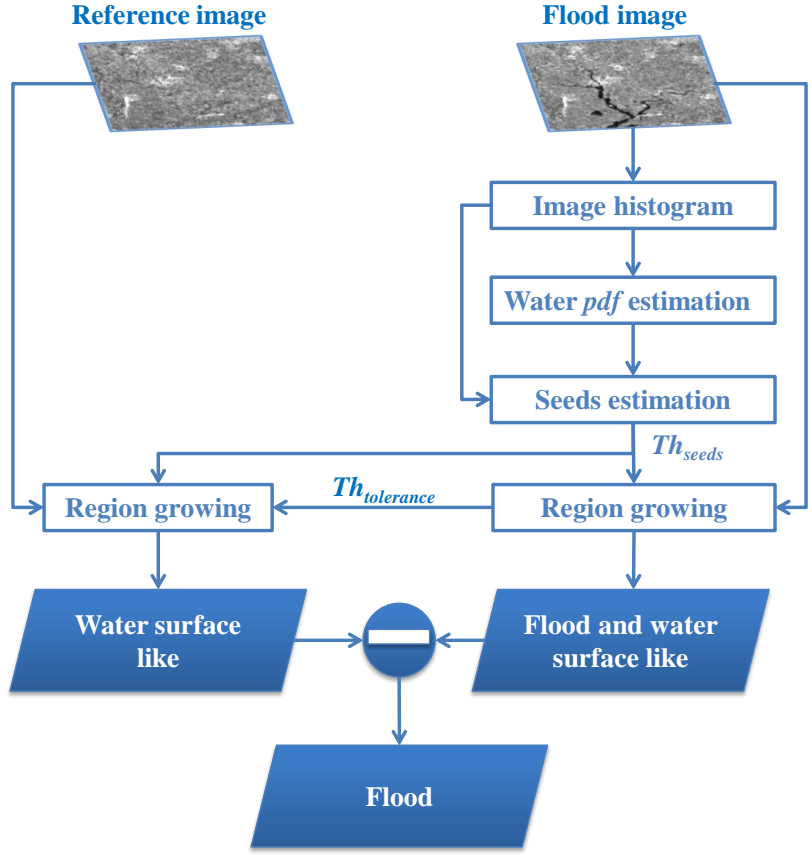

Figure 1. General scheme of the three processing steps of the flood detection algorithm.

We used Latin hypercube sampling (LHS) to take 1000 samples of the two uncertain LISFLOOD-FP parameters $r$ and channel Manning's roughness $n_{\mathrm{c}}$. LHS is a useful sampling scheme for multiple variables as the method can sample parameter values within a prior distribution in more than one dimension (Huntington and Lyrintzis, 1998). We used LHS here, as it is an efficient scheme that statistically represents the parameter space without repetitions (Beven, 2009; Pianosi et al., 2016).

\subsection{SAR image processing algorithm}

Because SAR satellites are capable of all-weather day and night observations and can distinguish the differences between land and open water signal returns, they are particularly useful for observations of flooding. To derive flood extent maps from the SAR images, we adopted the method proposed by Matgen et al. (2011) and developed by Giustarini et al. (2013) and Chini et al. (2016). This method has three steps as illustrated in Fig. 1. Firstly, the probability density function (pdf) of the open water backscatter values in the SAR data is estimated. This requires identification of the bimodal aspect to a histogram of backscatter values so that "open water" values can be recognised from other backscatter values. A theoretical pdf of water backscatter is then fitted to this histogram using nonlinear regression techniques. The backscatter threshold value $\left(\mathrm{Th}_{\text {seeds }}\right)$ where this pdf starts to diverge from the histogram is identified. Then, isolating those pixels with backscatter values lower than this threshold produces a preliminary flood map (region growing seeds). The sec- 
Table 1. Contingency table (after Stephens et al., 2014 and Mason, 2003).

\begin{tabular}{|c|c|c|c|}
\hline & \multicolumn{2}{|c|}{ Modelled } \\
\hline & & Water & No water \\
\hline $\begin{array}{l}\vec{D} \\
\stackrel{D}{D} \\
0 \\
0\end{array}$ & $\begin{array}{l}\text { Water } \\
\text { No water }\end{array}$ & $\begin{array}{l}\text { (A) Correct water (hits) } \\
\text { (B) Over-prediction (false alarms) }\end{array}$ & $\begin{array}{l}\text { (C) Under-prediction (misses) } \\
\text { (D) Correct no water (correct rejections) }\end{array}$ \\
\hline
\end{tabular}

ond step is to apply a region growing approach to grow the flooded areas within the preliminary flood map until a tolerance threshold level is reached ( $\left.T h_{\text {tolerance }}\right)$. For the SAR image, this step refines the extent of pixels with an open water value.

In the last step, a reference image is used to remove pixels from the flood map that do not change between the flood and non-flood images (Hostache et al., 2012) - i.e. pixels which have "water-surface-like" radar responses and could be either bodies of permanent water or smooth surfaces such as car parks or flat roofs. This third step creates the final binary map of flood extent. Errors inherent in the SAR processing are, for simplicity, not considered in this paper.

\subsection{Performance measures}

We compare these SAR-derived flood maps against the simulated flood maps generated from LISFLOOD-FP output at the equivalent time step by using a contingency matrix shown in Table 1. Flood maps are compared pixel to pixel to determine if there is agreement or disagreement between the two paired maps on whether there is surface water present or not.

From this, a binary pattern performance measure is used to give a deterministic indication of how well each LISFLOODFP-simulated flood map has represented the observed data (Mason, 2003; Stephens et al., 2014). We chose to use the critical success index (CSI, Eq. 1) as this measure does not consider "correct rejections" - (D) in Table 1 - in the calculation (Bates and De Roo, 2000; Horritt et al., 2001; Aronica et al., 2002) and it weights over- and under-prediction equally - B and C - respectively. CSI scales between 1 (indicating perfect skill in the model) and 0 (indicating no skill in the model).

$\mathrm{CSI}=\frac{\mathrm{A}}{\mathrm{A}+\mathrm{B}+\mathrm{C}}$

If correct rejections were included by the use of a different performance measure, the result would be overly optimistic scores, given the large areas of no water normally observed in a SAR image. All LISFLOOD-FP-simulated flood maps would seem to perform exceptionally well with little to help differentiate between each simulation.

Before comparing SAR and LISFLOOD-FP model results, an independent remote dataset is used to illustrate the impact of observation errors and gaps inherent in the SAR data from processing. This validation step makes use of a very highresolution $(0.2 \mathrm{~m})$ aerial photograph taken by the Environment Agency of England and Wales (EA) on 24 July 2007 from an aircraft passing over at 11:30 GMT (details within Giustarini et al., 2013). A flood map shapefile was created from this imagery by manual definition of the flood boundary. This was then converted and upscaled to a raster with the same spatial resolution $(75 \mathrm{~m})$ of the LISFLOOD-FP model results. Both the ENVISAT data and the LISFLOOD-FP results (the highest-scoring models) are compared with these aerial data. A figure showing these flood extents and the CSI results from this comparison are given in Sect. 4.1 below.

\subsection{Parameter identifiability}

To determine most likely values for $r$ and $n_{\mathrm{c}}$, we follow the technique of Wagener et al. (2003) in applying a DYNIA method to the ensemble of CSI score results. Since the original DYNIA method was applied to continuous data and not discrete observations, some changes are needed which are described at the end of this section.

The first stage in the DYNIA method is to rescale the "objective function" (i.e. CSI scores) so that they add up to 1 , which is done by dividing each model result by the sum of all scores. Next, computing the cumulative distribution of the rescaled objective function transforms the objective function into a support measure which sums to unity - the "cumulative support" - so that each support measure may be comparable. To obtain the information content (IC), a confidence limit is applied to the rescaled objective functions to exclude outliers. The width of the confidence limit depends on how the best-performing parameters are spread within the parameter space: a wide confidence limit suggests that the parameters are distributed within the parameter space evenly and IC is low, whereas a narrow confidence limit suggests that the best-performing parameters are located within a smaller range and $\mathrm{IC}$ is higher. To normalise results for these data, a transformation measure was used (1 minus the width of the confidence limits over the parameter range, normalised to run from 0 to 1 ), so a value close to 1 is equivalent to a high IC. The IC can have any value between 0 (no information in that observation for parameter identification purposes) and 1 
(observation is most informative for the parameter). The IC results are shown in Sect. 4.2 below.

The second stage in DYNIA is to find the identifiability by locating where in the parameter-time space most parameter information can be found. This is achieved by examining a plot of cumulative support against a parameter value. Any deviation from a straight line gradient of this cumulative support indicates whether the parameter is conditioned by the objective function or not. The stronger the deviation, the stronger the conditioning/identifiability of the parameter variable. This is done using the marginal parameter distributions - interactions are therefore only implicitly accounted for. The final stage is to organise the data into bins and calculate the gradient of the cumulative support between them. The results from this examination are shown in Sect. 4.3 below. These results are represented using plots of the gradient of the cumulative support value versus the parameter of interest to indicate the strength of the identifiability in each case. The IC and identifiability for all single SAR acquisitions are shown along with particular SAR combinations/groupings: by flood event and by position in the flood hydrograph as detailed in Sect. 3.2 and Table 3.

The original method proposed by Wagener et al. (2003) recommends a pre-selection of models before stage 1 by using only the top $10 \%$ performing models. We deviate from this original method by using the complete sample of 1000 sets of CSI scores since we found this gave a clearer overview picture of identifiability with our data.

The objective of this paper is to determine if a grouping of SAR data provides more information than single data. Here, the method of obtaining the CSI "group" score is also a small departure from the original DYNIA method. These group scores are determined by multiplying each single model/SAR flood map CSI result with the CSI score of the next SAR flood map until all members of the particular group have been added. The unique combinations which comprise these groups are described in Table 3. This combining of CSI scores is done for results from each of the 1000 models/parameter scenarios. The next step is the same as for single CSI scores as described above - i.e. to rescale the objective function and compute the cumulative support. So, although multiplying CSI values will reduce the grouped score, it has no bearing, as it is the changes to the gradient of the cumulative support value that indicates parameter identifiability, not the CSI scores themselves. The group IC and identifiability results shown in Sect. 4.2 and 4.3 result from SAR data that was grouped by this multiplication of CSI scores.

\section{Study area and data used}

The area around Tewkesbury (UK), located at the confluence of the Rivers Severn and Avon is our test location. Figure 2

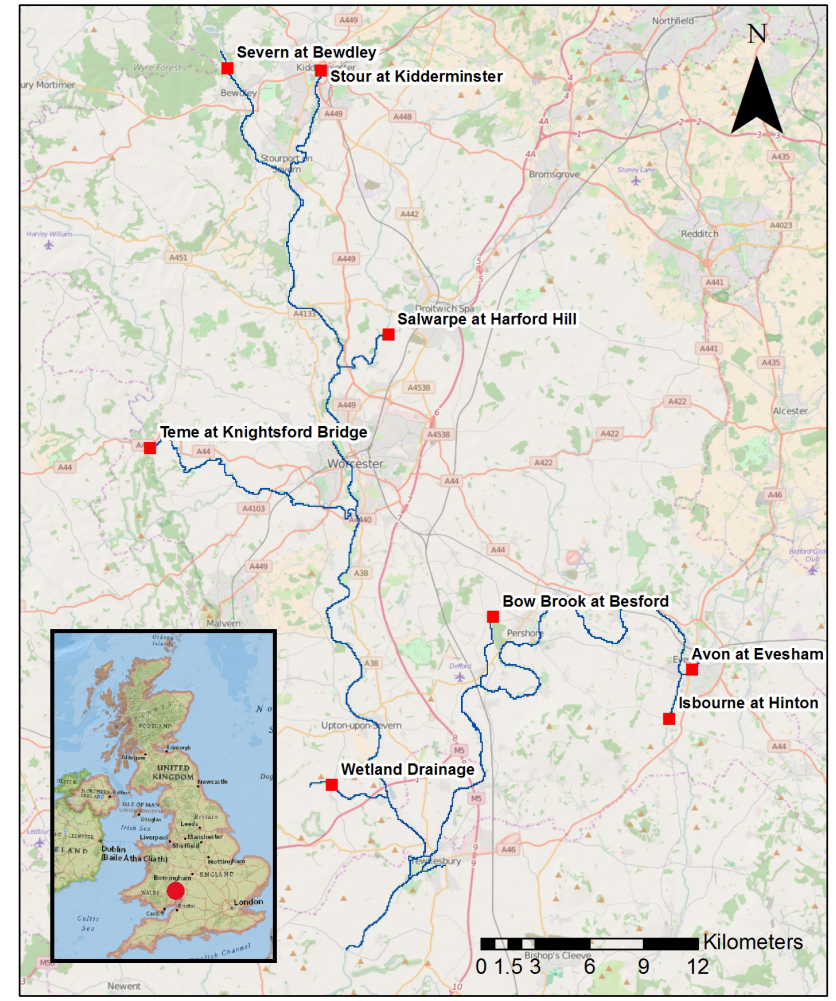

Figure 2. Extent of the River Severn model.

illustrates the $30.5 \mathrm{~km}$ by $52.4 \mathrm{~km}$ model domain, showing the two main rivers and their tributaries.

\subsection{River Severn model set-up}

Two separate LISFLOOD-FP models were created to test the methodology. Both models are at $75 \mathrm{~m}$ spatial resolution and use the same background DEM. Additionally, both models use the same gauged inflows and have a rectangular-shaped channel. At the lower end of the model, a "free" downstream boundary condition was applied with a fixed energy slope of 0.00007 , based on the average valley slope.

The differences between the two separate models are in how bankfull channel depth and Manning's channel roughness values are obtained. First, an "observed" model was created using surveyed cross sections of the main rivers to determine channel width and depth with a fixed Manning's channel roughness parameter of 0.038 (a value representing a main channel, which is clear with some winding and presence of stones/vegetation, from Chow, 1959). The crosssection survey data were provided by the EA. Second, a "test" model was created in which the depth parameter $r$ and Manning's channel roughness parameter $n_{\mathrm{c}}$ are determined using the DYNIA identifiability analysis as described in the previous section. The depth parameter $r$ was sampled between 0.0 and 0.5 so that the modelled river depth would never exceed half of the river width. This is a reasonable as- 
sumption for this site where the Severn is on average around $75 \mathrm{~m}$ wide (estimated from lidar data) with surveyed bankfull depth varying between 6 and $11 \mathrm{~m}$. The range of Manning channel roughness values for the sampling was set between 0.015 and 0.100 (Chow, 1959). A low $n_{\mathrm{c}}$ of 0.015 would represent a channel, which is clear and straight, whereas a high $n_{\mathrm{c}}$ value of 0.100 would represent a channel with very thick vegetation/submerged branches present. This range widely encompasses recommended roughness values for the rivers present within the study domain.

For both the test and observed models, the Manning floodplain roughness value was set at a standard 0.06 for the entire domain. This is a reasonable average for the floodplain which is mainly crop and grassland (0.03-0.04) but with the presence of some trees (0.12) and brush (0.07). The Manning values for the floodplain and the river channel $\left(n_{\mathrm{c}}\right)$ are assumed to be spatially and also temporally invariant. The floodplain topography was taken from a $2 \mathrm{~m}$ resolution lidar-based digital surface model (DSM) with vertical RMSE of $0.10 \mathrm{~m}$ taken on 9 December 2005 by the EA. The EA treated the DSM to remove structures and vegetation, and we then spatially averaged this digital terrain model (DTM) to $75 \mathrm{~m}$ resolution, as this is an appropriate compromise between model fidelity and computational cost for rural river reaches (Horritt and Bates, 2001). The $75 \mathrm{~m}$ DTM was further processed to reinsert the maximum height of the flood embankments along the reach in order to preserve normal flood behaviour along the river banks. No bridges or weirs are included in the model. Neal et al. (2011) and Garcia-Pintado et al. (2013) provide additional details of the model set-up for the River Severn around Tewkesbury.

Observed flows obtained from the EA were used as inflow to both models. Forcing flows come principally from the gauging station on the River Severn at Bewdley but with additional inputs from three tributaries of the River Severn: River Stour (at Kidderminster), River Salwarpe (at Harford Hill near Droitwich Spa) and River Teme (at Knightsford Bridge near Knightwick). For the River Avon, flows from the Evesham gauging station were used, with two additional flow contributions from the Avon tributaries Bow Brook (at Besford) and the River Isbourne (at Hinton). A smaller input from a wetland area west of Tewkesbury was also included, with flows scaled by area from the Salwarpe gauged flows.

The River Severn flood events of March 2007 (simulation period: 19 February-29 April 2007), July 2007 (simulation period: 5 June-12 August 2007), January 2008 (simulation period: 26 November 2007-25 February 2008) and January 2010 (simulation period: 4 January-18 February 2010) were modelled. The dates were chosen so the model would start at least 10 days before the start of the flood and end after flows had returned to within the banks.

\subsection{SAR observations of the River Severn}

Historic ENVISAT wide swath mode (WSM, $150 \mathrm{~m}$ resolution) data are available from the European Space Agency's ENVISAT catalogue. These were resized to $75 \mathrm{~m}$ resolution data. Previous research at this site has largely focused on the July 2007 flood event observations (Mason et al., 2012, 2014; Durand et al., 2014; Garcia-Pintado et al., 2013; Schumann et al., 2011). The present work makes use of other historic flood observations in this area - namely the floods of March 2007, January 2008 and January 2010. Details of the satellite acquisition times are shown in Table 2, along with hydrologic information on the flood taken from the gauging station at Saxons Lode in the middle of the model domain. Time to peak describes the number of hours between the start of the event and the peak of the flood. Flooding from sequential events or with high contributions from other sources such as groundwater will therefore have a greater time to peak.

We separated these 11 SAR observations into different categories by particular flood event (Sect. 4.3.2) or where the acquisition occurs on the flood hydrograph (Sect. 4.3.3). Table 3 shows how this segmentation of the 11 acquisitions into categories was devised.

\section{Results and discussion}

\subsection{CSI scores}

In this paper, we compare the results of hydraulic modelgenerated flood maps with the SAR observations of flood extent in order to determine if the satellite data have information in terms of calibrating the model. However, with inherent errors in the SAR data from processing, it is worthwhile first to compare the SAR data with those from other available remote data to illustrate the impact of observation errors. For validation, the CSI score is calculated between the ENVISAT data and an aerial photograph of the River Severn taken on 24 July 2007.

Figure 3 illustrates the derived flood extent from these aerial data (Fig. 3a) with the ENVISAT WSM SAR-derived flood map (Fig. 3b) from the previous day. Highest-scoring LISFLOOD-FP simulation flood maps from the observed model (Fig. 3c) and test model (Fig. 3d) at the same time step as the ENVISAT data are included for comparison. The CSI results from this SAR aerial and SAR-LISFLOOD-FP model comparison are shown in Table 4.

It is clear that the observed and test LISFLOOD-FP models produce lower CSI scores with the SAR data than with the aerial data. This is to be expected, and other studies which have used higher-resolution SAR imagery for validation (e.g. Bates et al., 2006; Di Baldassarre et al., 2009a, 2010) have observed the same result. The aerial photographderived flood map was delineated manually and therefore has improved representation of flooding because there are no de- 
Table 2. The European Space Agency (ESA) sourced ENVISAT ASAR WSM acquisitions used with equivalent flow and return period data for rivers Avon and Severn; gauged data were obtained from the EA.

\begin{tabular}{|c|c|c|c|c|c|c|c|}
\hline \multirow[t]{2}{*}{ SAR ID } & \multirow[t]{2}{*}{ Date } & \multirow[t]{2}{*}{ Time } & \multicolumn{3}{|c|}{ At Saxons Lode (Severn) } & \multicolumn{2}{|c|}{ At Evesham (Avon) } \\
\hline & & & $\begin{array}{r}\text { Time to } \\
\text { flood } \\
\text { peak } \\
\text { (approx., h) }\end{array}$ & $\begin{array}{l}\text { Gauged } \\
\text { flow } \\
\left(\mathrm{m}^{3} \mathrm{~s}^{-1}\right)\end{array}$ & $\begin{array}{r}\text { Event } \\
\text { return } \\
\text { period } \\
\text { (approx.) }\end{array}$ & $\begin{array}{r}\text { Gauged } \\
\text { flow } \\
\left(\mathrm{m}^{3} \mathrm{~s}^{-1}\right)\end{array}$ & $\begin{array}{r}\text { Event } \\
\text { return } \\
\text { period } \\
\text { (approx.) }\end{array}$ \\
\hline $1($ March 2007,1$)$ & 5 Mar 2007 & $10: 27$ & 268 & 388 & \multirow{4}{*}{$<5$} & 188 & \multirow{4}{*}{$<3$} \\
\hline $2($ March 2007, 2) & 5 Mar 2007 & $21: 53$ & 268 & 405 & & 87 & \\
\hline $3(\operatorname{March} 2007,3)$ & 8 Mar 2007 & $10: 34$ & 268 & 419 & & 55 & \\
\hline $4($ March 2007, 4) & 8 Mar 2007 & $21: 58$ & 268 & 400 & & 45 & \\
\hline 5 (July 2007,1 ) & $23 \mathrm{Jul} 2007$ & $10: 27$ & 132 & 532 & \multirow{2}{*}{$30-40$} & 196 & \multirow{2}{*}{$110-150$} \\
\hline 6 (July 2007, 2) & 23 Jul 2007 & $21: 53$ & 132 & 512 & & 167 & \\
\hline 7 (January 2008,1$)$ & 17 Jan 2008 & $21: 55$ & 228 & 432 & \multirow{3}{*}{$<5$} & 64 & \multirow{3}{*}{$<3$} \\
\hline 8 (January 2008, 2) & 24 Jan 2008 & $10: 12$ & 228 & 440 & & 28 & \\
\hline 9 (January 2008, 3) & 24 Jan 2008 & $21: 38$ & 228 & 433 & & 26 & \\
\hline 10 (January 2010,1$)$ & 18 Jan 2010 & $10: 30$ & 73 & 407 & \multirow{2}{*}{$<3$} & 107 & \multirow{2}{*}{2} \\
\hline 11 (January 2010, 2) & 18 Jan 2010 & $21: 53$ & 73 & 403 & & 37 & \\
\hline
\end{tabular}

Table 3. Description of SAR groupings.

\begin{tabular}{|c|c|c|c|c|c|c|c|c|c|c|c|}
\hline \multirow[t]{2}{*}{ Description } & \multicolumn{11}{|c|}{ SAR ID } \\
\hline & 1 & 2 & 3 & 4 & 5 & 6 & 7 & 8 & 9 & 10 & 11 \\
\hline By flood event & \multicolumn{4}{|c|}{ March 2007} & \multicolumn{2}{|c|}{ July 2007} & \multicolumn{3}{|c|}{ January 2008} & \multicolumn{2}{|c|}{ January 2010} \\
\hline $\begin{array}{l}\text { By point in hydrograph }(r=\text { rising } \\
\operatorname{limb}, p=\text { peak, } f=\text { falling limb })\end{array}$ & r & $\mathrm{r}$ & $\mathrm{f}$ & $\mathrm{f}$ & $\mathrm{f}$ & $\mathrm{f}$ & $\mathrm{p}$ & $\mathrm{f}$ & $\mathrm{f}$ & $\mathrm{p}$ & $\mathrm{p}$ \\
\hline
\end{tabular}
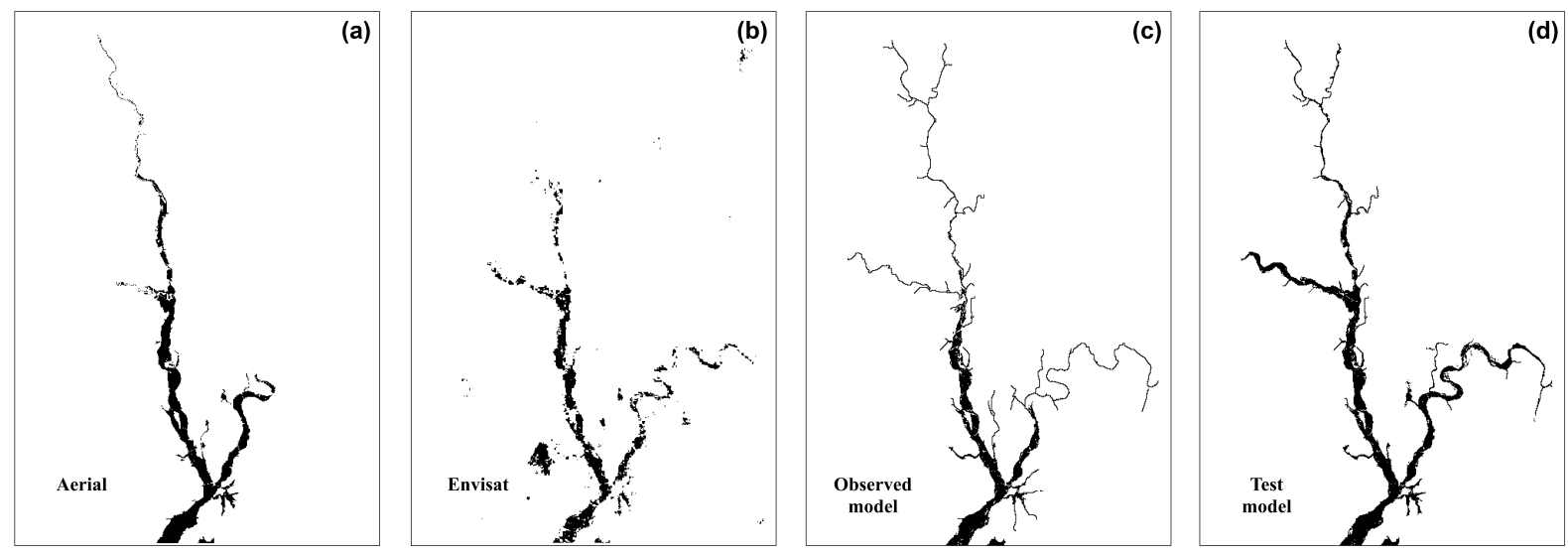

Figure 3. The July 2007 flood extents as observed by aerial photography (on 24 July 2007 at 11:30 GMT, a) and ENVISAT ASAR instruments in WSM (on 23 Jul 2007 at 10:27 GMT, b). The same flood event simulated in LISFLOOD-FP with surveyed cross sections (c, with Manning's channel roughness fixed at 0.038 ) and the test model with optimally calibrated parameters (d).

tection gaps in the flood extent, whereas SAR-derived flood extents rely on the correct detection of areas of water using a procedure which is vulnerable to issues of detection and processing. So while we may conclude that aerial imagery has the best level of detail in flood extent available here, these data can also be limited by observation extent and processing (i.e. manual delineation of the flood edge is still interpretive) and, as a resource, aerial imagery is not as frequently available as SAR data for observing flood events. It is also worth pointing out that, for the ENVISAT SAR data, describ- 
Table 4. CSI scores for July 2007 flood extent maps comparing results obtained using ENVISAT WSM SAR- and aerial-derived flood extents with hydraulic-model-generated flood extent.

\begin{tabular}{lcc}
\hline Flood map & $\begin{array}{c}\text { Aerial- } \\
\text { photograph } \\
\text { derived }\end{array}$ & $\begin{array}{c}\text { ENVISAT } \\
\text { derived }\end{array}$ \\
\hline Aerial-photograph derived & - & 0.47 \\
Observed model (not calibrated) & 0.74 & 0.43 \\
Test model & 0.75 & 0.46 \\
\hline
\end{tabular}

ing flood extent using the semi-automated algorithm can be a faster solution than manually delineating flood extent from new photographs.

The scores and flood extent for the observed model are not better than the test model results as might be expected. This may be explained by the fact that while the bathymetry of the observed model does come from survey data, the (domain-average) channel roughness value is not calibrated in either model. While the test model had 1000 parametervarying depth and roughness values, the observed model had a best estimate of domain-average channel roughness parameter (of 0.038). While appropriate for the main rivers, it is evident that the channel roughness value is not suitable for the narrower tributaries.

It is also of interest that when the aerial data are compared with the ENVISAT WSM SAR-derived flood maps (row 1, last column), CSI scores are similar to those obtained from the best hydraulic model results. This indicates that the hydraulic models are representing the observed flood extent for this flood accurately, within the limits of the available data. While sections of the flood are missing in the SAR data (for example, upper River Avon and River Severn) bias can be introduced. Ideally, these non-informative areas of the SAR data would be masked out to limit the impact, but with series of data each differently capturing a flood event this requires a more comprehensive analysis than available here. It is currently an active area of research; for example, Giustarini et al. (2016) propose flood probability maps from sequences of SAR data. These maps could be used to mask out low probability of flooding areas. Also Schlaffer et al. (2015) makes use of harmonic analysis to refine flood extent mapping - a mask could be created to obscure pixels with low signal to noise ratios.

The first step in the methodology is to examine the accuracy of the test model with changing parameter value using CSI. The ENVISAT WSM SAR and LISFLOOD-FP CSI results were plotted against the $r$ and $n_{\mathrm{c}}$ parameter variables and are presented in Fig. 4. This figure includes only two plots: one for an ENVISAT WSM acquisition taken on 23 July 2007 (10:27 GMT) and one taken on 24 January 2008 (10:12 GMT), but these CSI results represent typical results for the entire SAR data available.
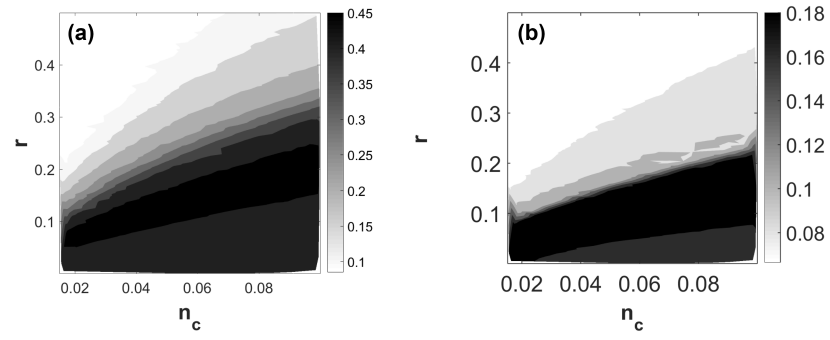

Figure 4. Single SAR acquisitions are compared with LISFLOODFP modelled flood maps. (a) Results from the SAR acquisition on 23 July 2007 at 10:27 GMT, (b) results from the SAR acquisition 24 January 2008 at 10:12 GMT.

The black areas in Fig. 4 show that a number of $r$ and $n_{\mathrm{c}}$ parameter combinations/models are able to produce a good result (i.e. equifinality as described by Beven, 2009). The optimal $r$ parameter range varies slightly depending on the image considered. Here, test models with the best reproduction of the SAR flood map have $r$ parameters between approximately 0.10 and 0.30 (July 2007) and between 0.07 and 0.25 (January 2008). Generally, the best reproduction of the SAR flood maps is obtained with models that have an $r$ value in the smaller parameter range which translates to a wide and shallow river channel.

Figure 4 also illustrates the covariance and a linear dependency between the two parameters. This was observed in all the SAR data. Although the choice of parameter range emphasises it, there is a slightly greater skill score sensitivity to changes in $r$ than for $n_{\mathrm{c}}$. This is to be expected since changes in channel depth would have an immediate and local impact on flood level and flood extent. It is logical therefore to see changes in $r$ producing a marked change in flood extent. Channel roughness changes by contrast have an impact more on flow velocities, consequently impacting on the timing of flood wave propagation through the channel (as discussed in Neal et al., 2015). This would have a more spatially diffuse impact on flood extent that is barely perceptible here.

Previous SAR-based assimilation studies (Hostache et al., 2009; Mason et al., 2009; Di Baldassarre et al., 2009a) show that with a known and fixed channel bathymetry there is sufficient sensitivity in the roughness parameter to enable calibration. The above findings indicate that the sensitivity of $n_{\mathrm{c}}$ is less obvious when $r$ is also unknown. There are previous studies also where, as here, channel friction appears less sensitive when other parameters are simultaneously calibrated. Roux and Dartus (2008), for example, found sensitivity in hydraulic model response to channel roughness to be weaker than sensitivity to geometry parameters and boundary conditions within a generalised sensitivity analysis framework. Additionally, Garcia-Pintado et al. (2015) found that sensitivity to bathymetry parameters dominated when using the ensemble transform Kalman filter to simultaneously estimate bathymetry and channel friction. The sensitivity in channel 
friction may therefore be not as obvious when other parameters are simultaneously calibrated because the model is no longer compensating for previously unrepresented uncertainties. It could be suggested that channel friction is reverting to its true sensitivity and so when channel friction is combined with more dominant parameters such as channel bathymetry it is rendered less useful for model calibration.

Consequently, an important result of this paper is that in this particular experimental set-up with channel roughness parameter $n_{\mathrm{c}}$ examined simultaneously with the channel depth parameter $r$ for the available ENVISAT SAR data $n_{\mathrm{c}}$ has a much reduced sensitivity compared with the $r$ depth parameter response. It is observed that $n_{\mathrm{c}}$ will yield optimal results for as long as $r$ is also unknown. This lack of sensitivity of channel roughness in this and all subsequent results meant that $n_{\mathrm{c}}$ could not be identified with any real confidence with this methodology (while $r$ is also unknown). So while $n_{\mathrm{c}}$ analysis was carried out, from this point onwards only those results from the more identifiable $r$ parameter are shown. $n_{\mathrm{c}}$ results are now omitted (but can be provided upon request if they are of interest).

\subsection{Information content (IC)}

Table 5 presents IC results for depth parameter $r$. For single SAR observations (left column), there is clearly greater information content in the July 2007 flood event images. The inundation during this higher-magnitude event extended well into the floodplain, and the flood detection algorithm was able to detect a large number of flooded cells. The lower IC scores for the March 2007, January 2008 and January 2010 events show that these observations contain less information to help estimate parameter $r$.

Grouping SAR data boosts the IC scores considerably, as can be seen in the right-hand side columns of Table 5. Group IC scores are estimated after the SAR data have been grouped together and CSI scores combined as described in Sect. 2.4. Different SAR groupings were tested as illustrated in Table 3 including combinations according to flood event, position on the hydrograph as well as all SAR data.

For IC, the July 2007 flood now no longer outperforms the rest and instead combinations of images, like the March 2007 flood event, have greater information on $r$. The March 2007 flood combination combines observations either side of the hydrograph peak and the January 2008 flood combination observes flooding "at peak" and soon after in the "falling limb". By contrast, the reduced-scoring January 2010 and July 2007 combinations acquired images at a single stage in the hydrograph only. We might conclude that the detection quality of the SAR flood maps and timing of acquisition must influence the final IC score and this is supported also by the observation that the early falling limb grouping has one of the largest IC scores here.

Nevertheless, the number of SAR flood maps combined appears to be important also since the all SAR and early
Table 5. Information content for $r$ from SAR observations and groups of SAR observations with a $90 \%$ confidence limit applied.

\begin{tabular}{lclc}
\hline Sequence & $\begin{array}{c}\text { Information } \\
\text { content }\end{array}$ & Sequence & $\begin{array}{c}\text { Information } \\
\text { content }\end{array}$ \\
\hline 1 - Mar07_1 & 0.10 & Rising limb & 0.13 \\
2-Mar07_2 & 0.11 & Peak of hydrograph & 0.23 \\
3 - Mar07_3 & 0.11 & Falling limb & 0.64 \\
4-Mar07_4 & 0.11 & March 2007 event & 0.50 \\
5 - Ju107_1 & 0.16 & July 2007 event & 0.37 \\
6-Ju107_2 & 0.19 & January 2008 event & 0.25 \\
7 - Jan08_1 & 0.10 & January 2010 event & 0.14 \\
8 - Jan08_2 & 0.11 & All SAR (1-11) & 0.68 \\
9-Jan08_3 & 0.11 & & \\
10-Jan10_1 & 0.10 & & \\
11-Jan10_2 & 0.10 & & \\
\hline
\end{tabular}

falling limb (just over half of these SAR images; Table 3) groupings emerge as providing the highest IC. The March 2007 flood grouping also contains twice as many members as the July 2007 or January 2010 flood groupings and outperforms both. Clearly, incorporating data from multiple observations improves IC since combining SAR images (and CSI scores) improves the likelihood of extracting information on the unknown parameters. However, it is not simply a question of numbers, otherwise falling limb (combining 6 SAR flood maps for an IC score of 0.64) would not be approaching the success of all SAR (combining 11 SAR flood maps for an IC score of 0.68). Nor is greater information necessarily revealed by removing poor scorers (the all SAR IC score reduces from 0.68 to 0.64 when the four lowest-scoring flood maps are removed from this grouping). Instead, the solution may lie in using SAR flood maps around the peak and falling limb of the flood since combining falling limb and "rising limb" observations together yields an IC score of 0.65 but combining falling limb and peak observations together provides an IC score of 0.67. Further work and data are necessary to draw any firm conclusions for the $r$ model parameter.

\subsection{Identifiability}

The identifiability of $r$ within single images and combinations of images is assessed in this section. This shows where the parameter is most easily identified in the ensemble of model results. A strong identifiability response would be marked by having a sharper peak in the following plots. The steeper the gradient, the stronger is the identifiability of the parameter. A sharper peak indicates that the best-performing parameters are concentrated in a small area of the parameter space. Conversely, a wider, shallower peak would indicate lower identifiability and that the best-performing models are widely distributed within the parameter range. 


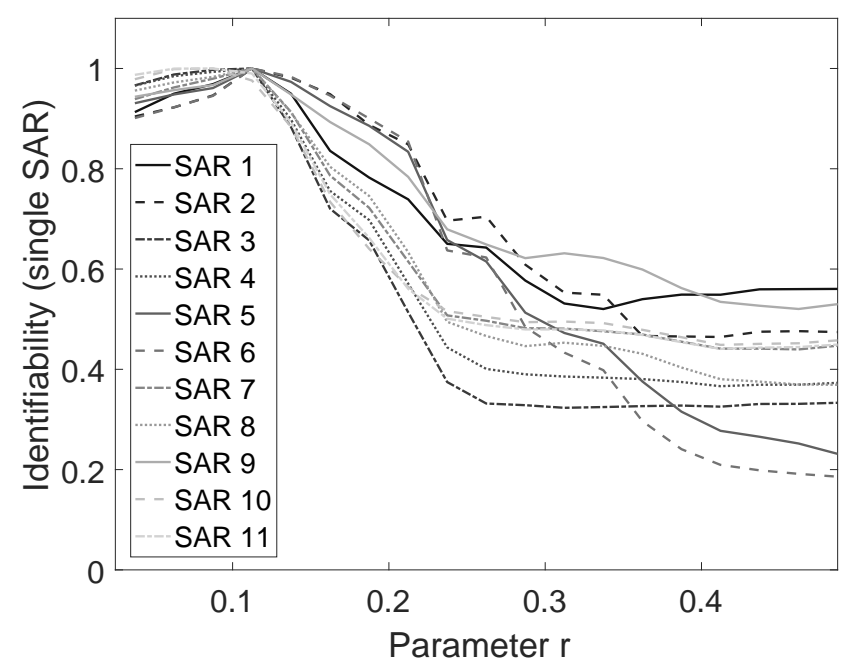

Figure 5. Identifiability against $r$ parameter for each ENVISAT SAR observation in our sample.

From the CSI contour plots as illustrated in Fig. 4, we see that the best-performing model parameter combinations are distributed fairly evenly within the parameter space, so a $90 \%$ confidence limit was also applied to the data prior to measuring the gradient of cumulative distribution of rescaled support values and creation of these following plots.

\subsubsection{Individual SAR observations}

Figure 5 shows the identifiability plots for all single SAR data, numbered as in Table 2. Because these plots do not generally have a strong peak, identifiability is relatively weak for the individual SAR observations. The strongest response here occurs for $r$ between 0.05 and 0.15 . The peaks are shaped differently for each SAR observation; SAR 4 and SAR 3 both have stronger identifiability (narrower peaks than the rest), whereas SAR 6 and SAR 2 are relatively weak in this ensemble by having wider peaks.

Taken collectively, these data provide inconclusive results. This generally weaker identifiability suggests that parameter $r$ would be difficult to identify within these data individually. The SAR data were acquired during different flood events (see Table 3) and their peaks occur at different $r$ parameter values. This variation may be due to differences in the size of flood extent (magnitude of flooding), the processing of the image or simply how the flood has developed.

\subsubsection{Flood event}

This section illustrates identifiability when data from individual SAR images are combined into flood events as indicated in Table 3. An important characteristic of the flood event identifiability plots is that the SAR acquisitions are taken together in close sequence. Garcia-Pintado et al. (2013) found that a tight sequence of images could improve model predic-

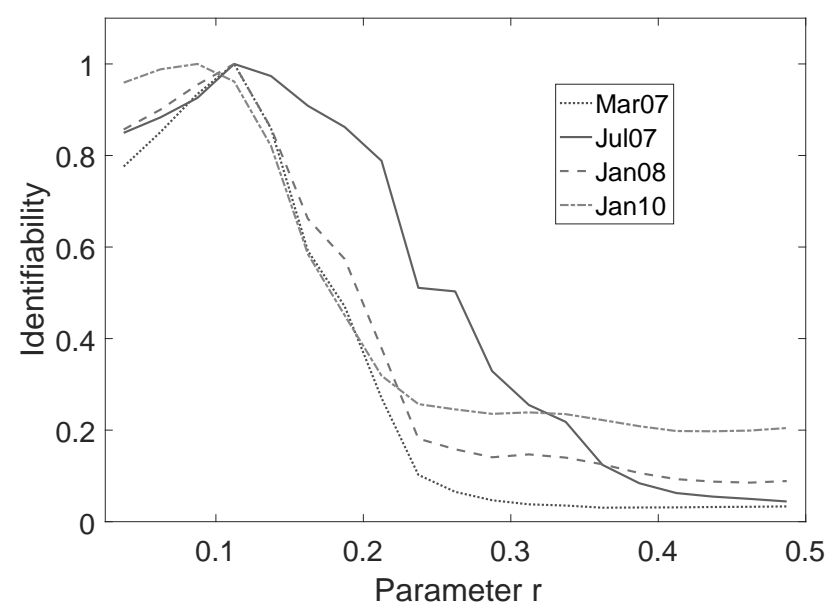

Figure 6. Identifiability against parameter $r$ for flood events.

tions. Combining observations in this way appears to focus the location of the $r$ parameter more clearly than is possible using single images.

Figure 6 shows that the March 2007 and January 2008 events produce a stronger identifiability between $r$ parameter values 0.07 and 0.15 . However, the optimum $r$ value varies between 0.07 to 0.1 and 0.1 to 0.15 depending on which of these floods is examined. It is entirely reasonable that identifiability of channel depth parameter in the data would vary with flood event as each flood is unique in magnitude and mechanism. Based on Fig. 6, the March 2007 and January 2008 SAR images might therefore be best utilised to locate the value of parameter $r$. These two events have approximately the same peak discharge flows at Saxons Lode (see Table 2). However, the IC results point towards the March 2007 data combination alone as having more parameter information and the reason for this becomes clear when looking at the individual SAR maps of flood extent. The group of SAR images acquired in March 2007 combine to yield a more complete representation of the flood development than the combination from January 2008. So, although in Fig. 6 this identifiability plot shows that both March 2007 and January 2008 flood events would be useful to locate the parameter $r$, IC shows the information contained in the March 2007 flood maps to be of most value.

\subsubsection{Through the flood hydrograph}

Figure 7 looks at identifiability at three stages of a flood hydrograph for the $r$ parameter, namely from observations at the (late) rising limb, the peak and the (early) falling limbs (with reference to the stage hydrograph at Saxons Lode in the central portion of the model domain). The SAR data used for "through the hydrograph" groupings are described in Table 3. 


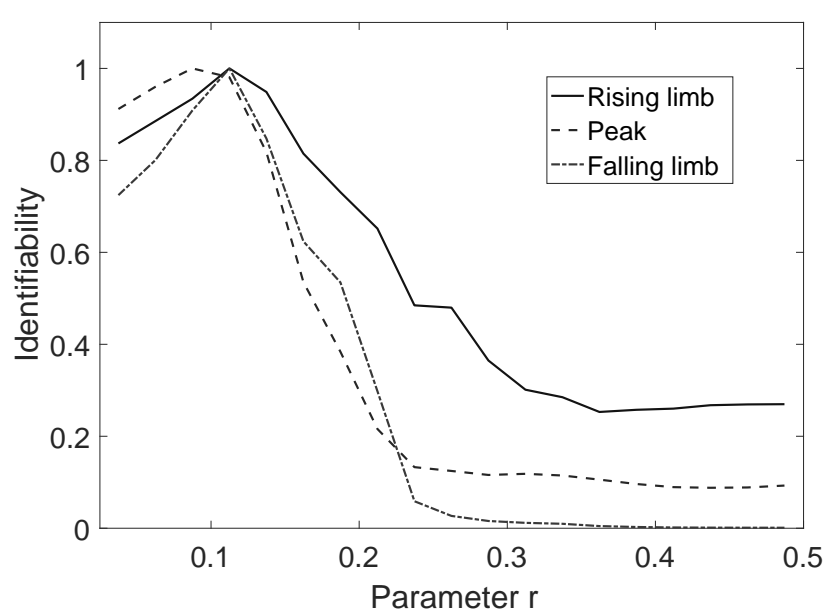

Figure 7. Identifiability against $r$ parameter for different stages in hydrograph.

Previous studies have found that the scheduling of SAR images is important for calibration of models. Di Baldassarre et al. (2009b) found that identification of the optimal model parameters depended on the timing of the SAR image acquisition and the magnitude of the flood event. GarciaPintado et al.'s (2013) paper established that to improve forecasting of water levels in a model, regular observations during the rising limb and then less frequent observations during the falling limb gave most success. Additionally, Schumann et al. (2009b) cautioned that SAR images acquired during the wetting and drying phases of a flood could be showing floodplain connections and dewatering processes unconnected with the hydraulics represented by the model.

While here the number of SAR data within each category is limited, Fig. 7 shows there is still a difference in identifiability for these separate phases. The strongest $r$ parameter identifiability occurs for those images taken around the flood peak and falling limb of the hydrograph. These lines have the steepest gradients and narrower peaks. Parameter $r$ is most identifiable between 0.1 and 0.2 in these data.

The weakest identifiability for the $r$ parameter occurs for the images taken during the rising limb as evidenced by the wider peak. Yet this result is in contrast to previous studies (e.g. Garcia-Pintado et al., 2013). The reasons for this disagreement with earlier research may simply lie with the way that through the hydrograph images were categorised. The method makes use of only a single independent gauge (at Saxons Lode) to define the phases, and as such it could be an oversimplification of the flood dynamics in a river catchment (such as where the rising, peak and falling limb of the flood occur at different times depending on where they are measured within the model domain). It might be more accurate to state that these flood extents observed around the peak and early falling limb capture the average moment of transition

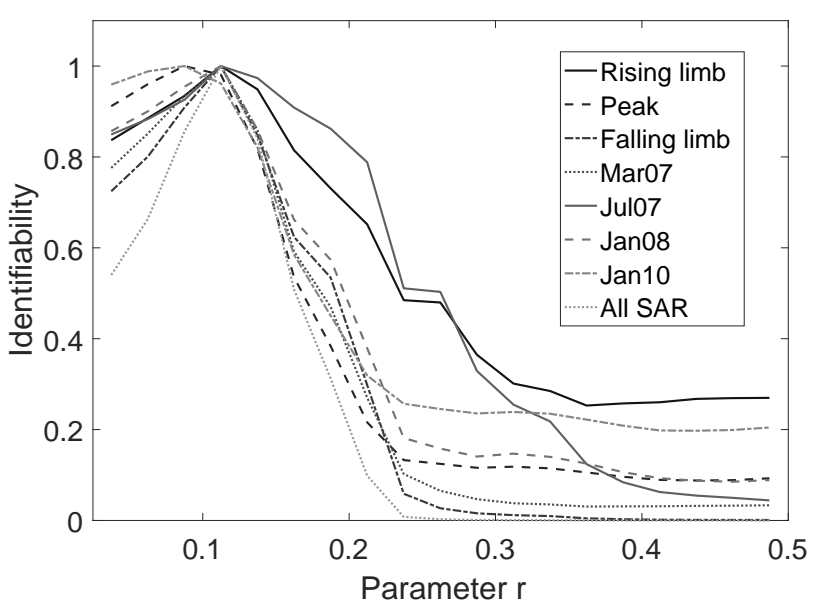

Figure 8. Identifiability against $r$ parameter for all hydrographs.

of flows over banks into the floodplain and these are better conditions for identifying channel depth parameters.

Alternatively this divergence of findings for the optimum image time could be explained by the different experimental set-up and goals. Garcia-Pintado et al. (2013) made use of distributed and derived water levels to correct model inflow errors and improve model predictions with assimilation, whereas identifiability here makes use of SAR-derived flood extent to calibrate reach-averaged bathymetry and roughness parameters for the entire river network. Information obtained during the rising limb was the most useful time to correct inflows because the water level and channel volumes are most changing during this time, whereas this experiment, in locating the optimum bathymetry and roughness parameters, relies on mapping of flood extent (i.e. at bankfull and overbank). This is seen most usually in the peak and falling limb images where there is indeed flood extent but also where flows (at some locations within the model domain) are transitioning between channel and floodplain.

\subsubsection{All data}

Figure 8 shows the identifiability result for all 11 SAR flood maps combined and compares it with all the previous group results so far. As for the IC results, this all SAR arrangement produces an observable improvement in identifiability compared with the single SAR or flood event plots. Although Sect. 4.3.1 shows that a single image does provide the information needed to locate parameter $r$, these results show that a grouping of similarly conditioned images can locate $r$ more distinctly and thus with greater confidence. Here, the strongest identifiability is for those models with $r$ between approximately 0.10 and 0.12 . Identifiability is particularly strong for the all SAR results.

These results suggest that greatest information for parameter $r$ can be obtained by making use of as much data as is available; in other words, by simply making use of all avail- 
able images, the depth parameter $r$ becomes more identifiable. Moreover, all SAR data incorporates data from different flood events and therefore represents a range of different flooding mechanisms. As such, the parameter $r$ might be considered more robustly calibrated. In this instance, including even relatively poor flood maps does not negatively impact the result. However, this might not always be true and situations may arise where particular flood maps (or sets of flood maps) would be disinformative.

\subsubsection{Constraining the channel roughness parameter $n_{\mathrm{c}}$}

The results above show that calibration is possible for the more dominant depth parameter but that roughness is less easily located in this simultaneous calibration methodology. So far, it is assumed that no ground data are available to give prior information on either parameter and so the ranges are deliberately broad. However, one or both parameters could be constrained further with some knowledge of the catchment and standard look-up tables (e.g. Phillips and Tadayon, 2006; Chow, 1959). Given that even a cursory examination of Google Earth imagery shows regions of meander and channel alteration, obstructions and changing vegetation along the River Severn reach, the Manning channel roughness values are more likely to lie between 0.035 and 0.055 . This section shows that if we constrain the $n_{\mathrm{c}}$ parameter to a narrower range based on physical principles and expert judgement, it is possible to improve on first results. We focus here on just the top-performing models (the maximum CSI score or within $2 \%$ of it) to remove outlying model results.

Figure 9 compares the identifiability for all SAR data for the full range of models (roughness is not constrained; solid line) and for 236 models which satisfy the constraint of having $n_{\mathrm{c}}$ between 0.035 and 0.055 (dashed line). Where there is no constraint on $n_{\mathrm{c}}$, the location of $r$ is most identifiable between approximately 0.10 and 0.12 in all SAR groupings. With $n_{\mathrm{c}}$ constrained, the $r$ value moves to a lower depth range of between approximately 0.08 and 0.10 . This translates to a reach-average model depth between 6 and $7.2 \mathrm{~m}$ and is reasonably close to the observed data. In this constrained group of models, the single highest-scoring model has $r$ of 0.086 $\left(n_{\mathrm{c}}\right.$ of 0.036$)$ and thus indicates the optimum reach-average model depth is around $6.51 \mathrm{~m}$. The equivalent rectangular depth from the EA survey is $5.63 \mathrm{~m}$ (assuming a reach median width of $76 \mathrm{~m}$ ) using bankfull cross-sectional area. The difference therefore between the calibrated value and the observed equivalent is approximately $0.88 \mathrm{~m}$ (an error of $16 \%$ ).

The model responds to changes in channel friction by altering the speed of the flood wave and flow velocities. These results highlight the important reasons for calibrating this second parameter concurrently. If channel roughness were set too high, the flood wave would be delayed. If it were set too low, the flood wave would be too advanced.

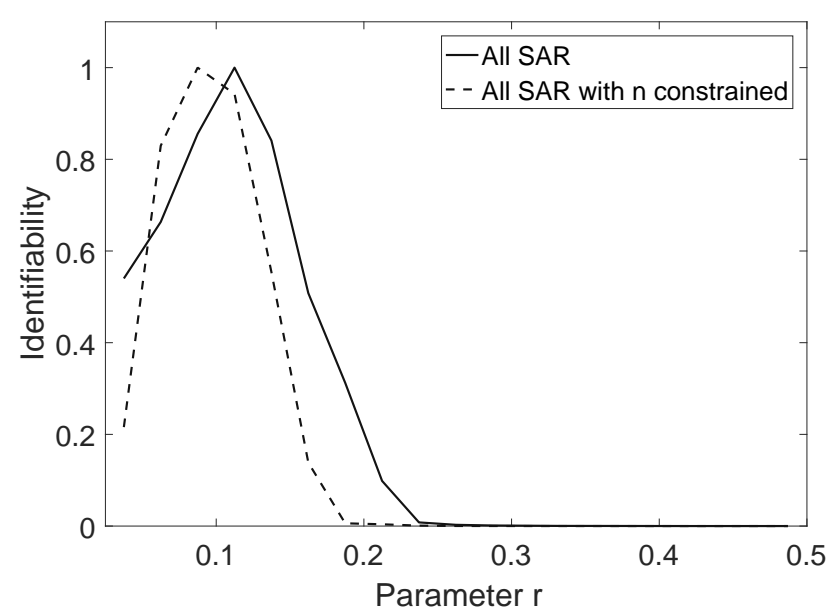

Figure 9. Identifiability for 23 July 2007 at 10:27 GMT showing all data (solid line) and with $n_{\mathrm{c}}$ restricted to between 0.035 and 0.055 (dashed line).

\section{Conclusion}

This paper presents a methodology for dual calibration of bankfull depth and channel roughness parameters of the LISFLOOD-FP sub-grid hydraulic model using SAR data and a binary pattern classification measure based on flood extent. Multiple models performed well initially, but by employing an identifiability methodology we located the area of the parameter space with highest information for the depth parameter $r$. The location narrows with the use of more SAR images.

The methodology provides some information on which single and combinations of SAR flood maps would be most useful for calibration purposes. Single SAR flood maps would be sufficient to calibrate the depth parameter but the identifiability is much improved when multiple maps are combined. Combinations aligned according to particular flood events/magnitudes are not conclusively different, but using many or all available SAR images does offer a real improvement in identifiability. There are indications that combining maps with similar flood duration or stage of flood (i.e. SAR images acquired close to peak or just after) would be beneficial for calibrating the reach-average depth parameter, but further work is needed with more targeted observations than the 11 used here. For robustness, a good range of flood magnitudes should be used for calibration.

The channel roughness parameter $n_{\mathrm{c}}$ was less sensitive to variations in flood extent and we failed to locate a representative value for this parameter when $r$ was also varied. The likely cause probably due to the initial range selected being too broad and the suggestion that depth/bathymetry is the more dominant parameter in the model which largely overrides, at this model scale at least, the significance of channel friction. By constraining $n_{\mathrm{c}}$ to a more plausible range it was possible to improve the calibration method and further 
improve the global estimate for the depth parameter. Under this constraint, the models with top CSI and identifiability results show that the reach-averaged depth parameter is calibrated to 0.086 , translating roughly to a reach-average depth of approximately $6.51 \mathrm{~m}$. This is an error of $0.88 \mathrm{~m}$ compared with an equivalent measure from observed cross-section data, where channel depth is approximated as $5.63 \mathrm{~m}$.

A benefit of this methodology is that, although we used gauged inflows within the model, in theory, the calibration methodology should work also with no recourse to ground data if good inflows can be simulated and a good DEM is available. The method also does not require a step to obtain water levels from the flood data. It does, however, make some simplifications and assumptions. First, the method assumes that as there are no errors in the return signals or processing of the ENVISAT WSM images and the derived flood maps therefore represent the true and full flood extent. In reality, there will be a chain of small errors in the processing of the data that would have an impact on the derived flood extent, and therefore also on the identifiability and IC results. This is particularly true for single SAR data which are compared against each other but perhaps less easily isolated in grouped SAR data as the combining of data smooths out errors and, by accumulation, compensates for perceived detection errors in the remotely sensed data. Understanding the impact of these individual errors on the final result would be an interesting follow-on experiment. The importance of the SAR resolution has not been tested here.

There is also error likely in the assumptions behind the model set-up. For example, we assume that the channel depth can be approximated with a parameter $r$, which is the ratio between channel depth to width at bankfull flow (i.e. $r$ is a linear scaling; as width varies, so does depth directly, in order to conserve water volumes). There is also the assumption that there is no rate of change between width and depth, so, in essence, depth and width do not vary along the modelled reach and are therefore uniform within the domain. This fixes $r$, width and depth to a single value per model, which is applied throughout the domain. This assumption cannot truly represent the reality of channel bankfull flows at particular points in the model, so it can only be used if there is an assumption that results represent a "reach-average" depth value for the entire modelled domain, based on a reach-average width. In this way, local variations in width, depth and flow can be smoothed out. Straight uniform channels are observed in natural systems only for short stretches of river, and so the methodology may be more appropriate within smaller subreaches (i.e. "sub-regions" or tributaries) where hydraulics and hydrology are similar or within medium-sized catchments with ostensibly negligible variation in domain channel width. Future work will investigate the applicability of the methodology under these conditions.
Competing interests. The authors declare that they have no conflict of interest.

Acknowledgements. We thank the Environment Agency of England and Wales for providing the river cross-section data, DEM and gauging station data. The authors would also like to thank the editor and two reviewers for their valuable comments which helped to improve the manuscript.

Melissa Wood's contribution was supported by the National Research Fund of Luxembourg through the PAPARAZZI project (CORE C11/SR/1277979).

Edited by: W. Wagner

Reviewed by: C. M. Massari and G. J.-P. Schumann

\section{References}

Andreadis, K. M., Clark, E. A., Lettenmaier, D. P., and Alsdorf, D. E.: Prospects for river discharge and depth estimation through assimilation of swath-altimetry into a raster based hydrodynamics model, Geophys. Res. Lett., 34, L10403, doi:10.1029/2007GL029721, 2007.

Aronica, G., Bates, P. D., and Horritt, M. S.: Assessing the uncertainty in distributed model predictions using observed binary pattern information with GLUE, Hydrol. Process., 16, 2001-2016, 2002.

Bates, P. D. and De Roo A. P. J.: A simple Raster-based Model for Flood Inundation Simulation, J. Hydrol., 236, 54-77, 2000.

Bates, P. D., Wilson, M. D., Horritt, M. S., Mason, D., Holden, N., and Currie, A.: Reach scale floodplain inundation dynamics observed using airborne Synthetic Aperture Radar imagery: data analysis and modelling, J. Hydrol., 328, 306-318, 2006.

Beven, K. J.: Environmental modelling: an uncertain future?, Routledge, London, New York, 60 pp., 2009.

Biancamaria, S., Durand, M., Andreadis, K. M., Bates, P. D., Boone, A., Mognard, N. M., Rodríguez, E., Alsdorf, D. E., Lettenmaier, D. P., and Clark, E. A.: Assimilation of virtual wide swath altimetry to improve Arctic river modelling, Remote Sens. Environ., 115, 373-381, 2011a.

Biancamaria, S., Hossain, F., and Lettenmaier, D. P.: Forecasting transboundary river water elevations from space, Geophys. Res. Lett., 38, 111401, doi:10.1029/2011GL047290, 2011 b.

Chini, M., Hostache, R., Giustarini, L., and Matgen, P.: A Hierarchical Split-Based Approach (HSBA) for automatically mapping flooded areas using SAR images of variable size and resolution, IEEE T. Geosci. Remote, in review, 2016.

Chow, V. T.: Open-channel hydraulics, McGraw-Hill, New York, 1959.

Di Baldassarre, G., Schumann, G., and Bates, P. D.: A technique for the calibration of hydraulic models using uncertain satellite observations of flood extent, J. Hydrol., 367, 276-282, 2009a.

Di Baldassarre, G., Schumann, G., and Bates, P.: Near real time satellite imagery to support and verify timely flood modelling, Hydrol. Process., 23, 799-803, 2009b.

Di Baldassarre, G., Schumann, G., Bates, P. D., Freer, J. E., and Beven, K. J.: Flood-plain mapping: a critical discussion of de- 
terministic and probabilistic approaches, Hydrolog. Sci. J., 55, 364-376, doi:10.1080/02626661003683389, 2010.

Di Baldassarre, G., Schumann, G., Brandimarte, L., and Bates, P.: Timely low resolution SAR imagery to support floodplain modelling: a case study review, Surv. Geophys., 32, 255-269, 2011.

Dilley, M., Chen, R. S., Deichmann, U., Lerner-Lam, A. L., and Arnold, M.: Natural Disaster Hotspots: A Global Risk Analysis, The World Bank, USA, 150 pp., 2005.

Domeneghetti, A., Tarpanelli, A., Brocca, L., Barbetta, S., Moramarco, T., Castellarin, A., and Brath, A.: The use of remote sensing-derived water surface data for hydraulic model calibration, Remote Sens. Environ., 149, 130-141, 2014.

Durand, M., Andreadis, K. M., Alsdorf, D. E., Lettenmaier, D. P., Moller, D., and Wilson, M.: Estimation of bathymetric depth and slope from data assimilation of swath altimetry into hydrodynamic model, Geophys. Res. Lett., 35, L20401, doi:10.1029/2008GL034150, 2008.

Durand, M., Rodriguez, E., Alsdorf, D. E., and Trigg, M.: Estimating river depth from remote sensing swath interferometry measurements of river height, slope, and width, IEEE J. Select. Top. Appl. Earth Obs. Rem. Sens., 3, 20-31, 2010.

Durand, M., Neal, J., Rodríguez, E., Andreadis, K. M., Smith, L. C., and Yoon, Y.: Estimating reach-averaged discharge for the River Severn from measurements of river water surface elevation and slope, J. Hydrol., 511, 92-104, 2014.

European Commission: http://ec.europa.eu/clima/policies/ adaptation/how/index_en.htm (last access: January 2016), 2014.

European Environment Agency: http://www.eea.europa.eu/media/ newsreleases/climate-change-evident-across-europe (last access: January 2016), 2012.

Garcia-Pintado, J., Neal, J. C., Mason, D. C., Dance, S. L., and Bates, P. D.: Scheduling satellite-based SAR acquisition for sequential assimilation of water level observations into flood modelling, J. Hydrol., 495, 252-266, 2013.

Garcia-Pintado, J., Mason, D. C., Dance, S. L., Cloke, H. K., Neal, J. C., and Bates, P. D.: Satellite-supported flood forecasting in river networks: a real case study, J. Hydrol., 523, 706-724, doi:10.1016/j.jhydrol.2015.01.084, 2015.

Giustarini, L., Matgen, P., Hostache, R., Montanari, M., Plaza, D., Pauwels, V. R. N., De Lannoy, G. J. M., De Keyser, R., Pfister, L., Hoffmann, L., and Savenije, H. H. G.: Assimilating SARderived water level data into a hydraulic model: a case study, Hydrol. Earth Syst. Sci., 15, 2349-2365, doi:10.5194/hess-152349-2011, 2011.

Giustarini, L., Hostache, R., Matgen, P., Schumann, G. J. P., Bates, P., and Mason, D. C.: A Change Detection Approach to Flood Mapping in Urban Areas Using TerraSAR-X, IEEE T. Geosci. Remote, 51, 2417-2430, doi:10.1109/TGRS.2012.2210901, 2013.

Giustarini, L., Hostache, R., Kavetski, D., Chini, M., Corato, G., Schlaffer, S., and Matgen, P.: Probabilistic Flood Mapping Using Synthetic Aperture Radar Data, IEEE T. Geosci. Remote, 54, 6958-6969, 2016.

Hall, J. W., Tarantola, S., Bates, P. D., and Horritt, M. S.: Distributed sensitivity analysis of flood inundation model calibration, J. Hydraul. Eng., 131, 117-126, doi:10.1061/(ASCE)07339429(2005)131:2(117), 2005.
Horritt, M. S. and Bates, P. D.: Effects of spatial resolution on a raster based model of flood flow, J. Hydrol., 253, 239-249, doi:10.1016/S0022-1694(01)00490-5, 2001.

Horritt, M. S., Mason, D. C., and Luckman, A. J.: Flood boundary delineation from synthetic aperture radar imagery using a statistical active contour model, Int. J. Remote Sens., 22, 2489-2507, 2001.

Hostache, R., Matgen, P., Schumann, G., Puech, C., Hoffmann, L., and Pfister, L.: Water Level Estimation and Reduction of Hydraulic Model Calibration Uncertainties Using Satellite SAR Images of Floods, IEEE T. Geosci. Remote, 47, 431-441, doi:10.1109/TGRS.2008.2008718, 2009.

Hostache, R., Matgen, P., and Wagner, W.: Change detection approaches for flood extent mapping: How to select the most adequate reference image from online archives?, Int. J. Appl. Earth Obs. Geoinf., 19, 205-213, 2012.

Hostache, R., Matgen, P., Giustarini, L., Teferle, F. N., Tailliez, C., Iffly, J.-F., and Corato, G.: A drifting GPS buoy for retrieving effective riverbed bathymetry, J. Hydrol., 520, 397-406, 2015.

Huntington, D. E. and Lyrintzis, C. S.: Improvements to and limitations of Latin Hypercube Sampling, Prob. Eng. Mech., 13, 245 253, 1998.

IPCC - Intergovernmental Panel on Climate Change: Climate Change 2014, Synthesis Report, https://www.ipcc.ch/pdf/ assessment-report/ar5/syr/SYR_AR5_SPMcorr2.pdf (last access: September 2015), 2014.

Legleiter, C. J. and Roberts, D. A.: A forward image model for passive optical remote sensing of river bathymetry, Remote Sens. Environ., 113, 1025-1045, 2009.

Marsh, T. J. and Hannaford, J.: UK Hydrometric Register, Hydrological data UK series, Centre for Ecology \& Hydrology, 210 pp. Wallingford, UK, 2008.

Mason, D. C., Cobby, D. M., Horritt, M. S., and Bates, P. D.: Floodplain friction parameterization in two-dimensional river flood models using vegetation heights derived from airborne scanning laser altimetry, Hydrol. Process., 17, 1711-1732, 2003.

Mason, D. C., Bates, P. D., and Dall'Amico, J. T.: Calibration of uncertain flood inundation models using remotely sensed water levels, J. Hydrol., 368, 224-236, 2009.

Mason, D. C., Schumann, G. J.-P., Neal, J. C., Garcia-Pintado, J., and Bates, P. D.: Automatic near real-time selection of flood water levels from high resolution synthetic aperture radar images for assimilation into hydraulic models: a case study, Remote Sens. Environ., 124, 705-716, 2012.

Mason, D. C., Garcia-Pintado, J., and Dance, S.: Improving flood inundation monitoring and modelling using remotely sensed data, Chartered Institution of Civil Engineering Surveyors, Civil Engineering Surveyor, 34-37, 2014.

Mason, I. B.: Binary Events. Forecast verification: a practitioner's guide in atmospheric science, John Wiley and Sons, Chichester, 2003.

Matgen, P., Montanari, M., Hostache, R., Pfister, L., Hoffmann, L., Plaza, D., Pauwels, V. R. N., De Lannoy, G. J. M., De Keyser, R., and Savenije, H. H. G.: Towards the sequential assimilation of SAR-derived water stages into hydraulic models using the Particle Filter: proof of concept, Hydrol. Earth Syst. Sci., 14, 17731785, doi:10.5194/hess-14-1773-2010, 2010.

Matgen, P., Hostache, R., Schumann, G., Pfister, L., Hoffmann, L., and Savenije, H. H. G.: Towards an automatic SAR-based flood 
monitoring system. Lessons learned from two case studies, Phys. Chem. Earth, 36, 241-252, 2011.

Mersel, M., Smith, L. C., Andreadis, K. M., and Durand, M. T.: Estimation of river depth from remotely sensed hydraulic relationships, Water Resour. Res., 49, 3165-3179, doi:10.1002/wrcr.20176, 2013.

Montanari, M., Hostache, R., Matgen, P., Schumann, G., Pfister, L., and Hoffmann, L.: Calibration and sequential updating of a coupled hydrologic-hydraulic model using remote sensingderived water stages, Hydrol. Earth Syst. Sci., 13, 367-380, doi:10.5194/hess-13-367-2009, 2009.

Moramarco, T., Corato, G., Melone, F., and Singh, V. P.: An entropy-based method for determining the flow depth distribution in natural channels, J. Hydrol., 497, 176-188, 2013.

Neal, J., Schumann, G. J. P., Fewtrell, T., Budimir, M., Bates, P., and Mason, D.: Evaluating a New LISFLOOD-FP Formulation with Data from the Summer 2007 Floods In Tewkesbury, UK, J. Flood Risk Manage., 4, 88-95, 2011.

Neal, J., Schumann, G., and Bates, P.: A subgrid channel model for simulating river hydraulics and floodplain inundation over large and data sparse areas, Water Resour. Res., 48, W11506, doi:10.1029/2012WR012514, 2012.

Neal, J. C., Odoni, N. A., Trigg, M. A., Freer, J. E., Garcia-Pintado, J., Mason, D. C., Wood, M., and Bates, P. D.: Efficient incorporation of channel cross-section geometry uncertainty into regional and global scale flood inundation models, J. Hydrol., 529, 169183, 2015.

Pappenberger, F., Cloke, H. L., Balsamo, G., Ngo-Duc, T., and Oki, T.: Global Runoff Routing with the Hydrological Component of the ECMWF NWP System, Int. J. Climatol., 30, 2155-2174, 2010.

Phillips, J. V. and Tadayon, S.: Selection of Manning's roughness coefficient for natural and constructed vegetated and nonvegetated channels, and vegetation maintenance plan guidelines for vegetated channels in central Arizona, US Geological Survey Scientific Investigations Report 2006-5108, US Geological Survey, p. 41, https://pubs.usgs.gov/sir/2006/5108/ (last acccess: December 2016), 2006.

Pianosi, F., Beven, K., Freer, J., Hall, J. W., Rougier, J., Stephenson, D. B., and Wagener, T.: Sensitivity analysis of environmental models: A systematic review with practical workflow, Environ. Model. Softw., 79, 214-232, 2016.

Roux, H. and Dartus, D.: Sensitivity Analysis and Predictive Uncertainty Using Inundation Observations for Parameter Estimation in Open-Channel Inverse Problem, J. Hydraul. Eng., 134, 541$549,2008$.
Schlaffer, S., Matgen, P., Hollaus, M., and Wagner, W.: Flood detection from multi-temporal SAR data using harmonic analysis and change detection, Int. J. Appl. Earth Obs. Geoinf., 38, 15-24, 2015.

Schumann, G., Matgen, P., Hoffmann, L., Hostache, R., Pappenberger, F., and Pfister, L.: Deriving distributed roughness values from satellite radar data for flood inundation modelling, J. Hydrol., 344, 96-111, 2007.

Schumann, G., Pappenberger, F., and Matgen, P.: Estimating uncertainty associated with water stages from a single SAR image, Adv. Water Resour., 31, 1038-1047, 2009a.

Schumann, G., Bates, P., Horritt, M. S., and Matgen, P.: Progress in Integration of Remote Sensing-Derived Flood Extent and Stage Data and Hydraulic Models, Rev. Geophys., 47, RG4001, doi:10.1029/2008RG000274, 2009b.

Schumann, G. J. P., Neal, J. C., Mason, D. C., and Bates, P. D.: The accuracy of sequential aerial photography and SAR data for observing urban flood dynamics, a case study of the UK summer 2007 floods, Remote Sens. Environ., 115, 2536-2546, 2011.

Stephens, E., Schumann, G., and Bates, P.: Problems with Binary Pattern Measures for Flood Model Evaluation, Hydrol. Process., 28, 4928-4937, 2014.

Tarpanelli, A., Brocca, L., Melone, F., and Moramarco, T.: Hydraulic modelling calibration in small rivers by using coarse resolution synthetic aperture radar imagery, Hydrol. Process., 27, 1321-1330, 2013.

Trigg, M. A., Wilson, M. D., Bates, P. D., Horritt, M. S., Alsdorf, D. E., Forsberg, B. R., and Vega, M. C.: Amazon flood wave hydraulics, J. Hydrol., 374, 92-105, 2009.

Wagener, T., McIntyre, N., Lees, M., Wheater, H. S., and Gupta, H. V.: Towards reduced uncertainty in conceptual rainfall-runoff modelling: Dynamic identifiability analysis, Hydrol. Process., 17, 455-476, 2003.

Yan, K., Tarpanelli, A., Balint, G., Moramarco, T., and Baldassarre, G. D.: Exploring the potential of SRTM topography and radar altimetry to support flood propagation modeling: Danube case study, J. Hydrol. Eng., 20, 04014048, doi:10.1061/(ASCE)HE.1943-5584.0001018, 2014.

Yoon, Y., Durand, M., Merry, C. J., Clark, E. A., Andreadis, K. M., and Alsdorf, D. E.: Estimating river bathymetry from data assimilation of synthetic SWOT measurements, J. Hydrol., 464, 363-375, 2012. 